\title{
Proteins in DNA methylation and their role in neural stem cell proliferation and differentiation
}

\author{
Jiaqi Sun ${ }^{1 *}$ D, Junzheng Yang ${ }^{1}$, Xiaoli Miao ${ }^{1}$, Horace H. Loh' ${ }^{1}$, Duanqing Pei ${ }^{1,2,3,4,5}$ and Hui Zheng ${ }^{1,2,3,4^{*}}$
}

\begin{abstract}
Background: Epigenetic modifications, namely non-coding RNAs, DNA methylation, and histone modifications such as methylation, phosphorylation, acetylation, ubiquitylation, and sumoylation play a significant role in brain development. DNA methyltransferases, methyl-CpG binding proteins, and ten-eleven translocation proteins facilitate the maintenance, interpretation, and removal of DNA methylation, respectively. Different forms of methylation, including 5-methylcytosine, 5-hydroxymethylcytosine, and other oxidized forms, have been detected by recently developed sequencing technologies. Emerging evidence suggests that the diversity of DNA methylation patterns in the brain plays a key role in fine-tuning and coordinating gene expression in the development, plasticity, and disorders of the mammalian central nervous system. Neural stem cells (NSCs), originating from the neuroepithelium, generate neurons and glial cells in the central nervous system and contribute to brain plasticity in the adult mammalian brain.
\end{abstract}

Main body: Here, we summarized recent research in proteins responsible for the establishment, maintenance, interpretation, and removal of DNA methylation and those involved in the regulation of the proliferation and differentiation of NSCs. In addition, we discussed the interactions of chemicals with epigenetic pathways to regulate NSCs as well as the connections between proteins involved in DNA methylation and human diseases.

Conclusion: Understanding the interplay between DNA methylation and NSCs in a broad biological context can facilitate the related studies and reduce potential misunderstanding.

Keywords: DNA methylation, Neural stem cells, DNA methyltransferases, Methyl-CpG binding proteins, Ten-eleven translocations, Vitamin C

\section{Background}

Epigenetics, the study of heritable changes in gene functions without changes in the actual genetic or underlying DNA sequence mechanisms (Bird 2007), is a fundamental mechanism in modulating gene expression in a particular cell type during development. DNA methylation, one of the main epigenetic modifications, non-coding

\footnotetext{
*Correspondence: sun_jiaqi@grmh-gdl.cn; zheng_hui@gibh.ac.cn

'Bioland Laboratory (Guangzhou Regenerative Medicine and Health

Guangdong Laboratory), \#188 Kaiyuan Ave., Science City, Huangpu District, Guangzhou 510700, China

Full list of author information is available at the end of the article
}

RNAs, and histone modifications are three predominant mechanisms. Particularly, in mammalian DNA, the principal modification is methylated cytosine, which is catalyzed by a family of DNA methyltransferase enzymes (DNMTs) (Goll and Bestor 2005) and predominantly occurs in $\mathrm{CpG}$ dinucleotide sequences to generate 5methylcytosine $(5-\mathrm{mC})$ on the pyrimidine ring ( $\mathrm{Zhu}$ 2009). DNA methylation in terminally differentiated cells was believed to be irreversible until the discovery of teneleven translocation (TET) enzymes in 2009 (Pastor et al. 2013). TET enzymes, identified as key players in active DNA demethylation process, can convert 5-mC 
into 5-hydroxymethylcytosine (5-hmC) (Tahiliani et al. 2009; Ito et al. 2010) and subsequently into 5formylcytosine (5-fC) and 5-carboxylcytosine (5-caC) (Ito et al. 2011). The functions of TET proteins in brain development attract much attention because the mammalian brain has the highest abundance of $5-\mathrm{hmC}$ among all the tissues investigated thus far (Kriaucionis and Heintz 2009; Globisch et al. 2010).

In mammalian embryogenesis, central nervous system (CNS) development begins with the induction of neuroectoderm, which forms the neural plate and then invaginates to generate the neural tube. Neural stem cells (NSCs) arise from neuroepithelial cells and the radial glia lining the neural tubes and differentiate into three major cell types in the CNS in a temporally defined sequence, with neurons appearing first, followed by astrocytes, and oligodendrocytes (Temple 2001; Kriegstein and Alvarez-Buylla 2009). After the completion of the initial embryonic development, multipotent NSCs are largely restricted to two germinal zones in rodent model, namely the subgranular zone (SGZ) of the dentate gyrus in the hippocampus and the subventricular zone (SVZ) along the lateral ventricular wall (Kempermann and Gage 1999; Ming and Song 2011). In a mouse study, adult hippocampal neurogenesis, which shares embryonic dentate neural progenitors, was found to be a continuous process from development (Berg et al. 2019). NSCs in the adult CNS sparkle the field that these preserved cells can be harnessed to repair injured or diseased brain. Therefore, the regulation of the proliferation and differentiation of NSCs is an important area of research. Significant advances to identify the dynamic roles of DNA methylation in brain development have been made. In this review, we highlight DNA methylation and DNA demethylation, focusing on the modulation of the proliferation and differentiation of NSCs.

\section{DNA methylation in NSC proliferation and differentiation \\ DNA methyltransferases}

DNA methylation is a major epigenetic mechanism for gene inactivation; it serves as the basis of silenced $\mathrm{X}$ chromosome and the establishment of parental-specific imprints during gametogenesis (Jaenisch and Bird 2003; Reik 2007). DNA methylation is catalyzed by a family of DNA methyltransferases (DNMTs), including DNMT1, DNMT3A, and DNMT3B (Goll and Bestor 2005). DNMT3A and DNMT3B are de novo methyltransferases, which are responsible for the covalent addition of a methyl group from S-adenosyl-l-methionine (SAM) to the $\mathrm{C} 5$ of cytosine in $\mathrm{CpG}$ dinucleotides, whereas DNMT1 mainly recognizes the hemimethylated DNA and maintains DNA methylation patterns in dividing somatic cells (Law and Jacobsen 2010). However, the classification is not tightly restricted. Limited evidence suggests the presence of de novo activity of DNMT1 (Okano et al. 1998; Yarychkivska et al. 2018; Arand et al. 2012), but the overall evidence was not immediately clear. In 2018, Zhu's group found the first systematic evidence confirming that DNMT1 functions as a de novo methyltransferase in vivo ( $\mathrm{Li}$ et al. 2018). It has been reported that inhibiting DNMT1-mediated de novo methylation by Stella is important for establishing DNA methylation pattern during oogenesis ( $\mathrm{Li}$ et al. 2018). Utilizing a "DNMT1-only" mouse embryonic stem cell line, a collaborative study by Xie's and Zhu's groups found that weak de novo methylation activity and imperfect maintenance methylation activity of DNMT1 can lead to spontaneous DNA methylation mutations (epimutations), which tend to be repaired by neighborguided correction based on the de novo and maintenance activities of DNMT1 in turn (Wang et al. 2020a). Additionally, the researchers found that the de novo and maintenance activities of DNMT1 vary in different genome regions, such as the enrichment of H3K9me2/3 areas with higher de novo activity and $\mathrm{CpG}$ islands with lower maintenance and de novo activities, thereby providing a new mechanism for maintaining different methylation levels in different regulatory sequences of the genome. Except for $\mathrm{CpG}$ methylation, other nonCpG sequences containing cytosine $(\mathrm{CpA} / \mathrm{C} / \mathrm{T})$ can be methylated (hereafter referred to as $\mathrm{mCpH}$ ) and have been found in embryonic stem cells (Lister et al. 2009; Ramsahoye et al. 2000) and neurons (Guo et al. 2014). Unlike most $\mathrm{mCpG}, \mathrm{mCpH}$ is established during postnatal neuronal maturation in both the mouse and human brains. de novo methyltransferase DNMT3A has been shown to induce non-CpG methylation (Ramsahoye et al. 2000). A study of DNA methylation at single-base resolution in human has revealed that the highly conserved non-CpG methylation accumulates in neurons but not in glia during postnatal development, a critical period of synaptogenesis and neural circuit maturation (Lister et al. 2013). The growing knowledge on non-CpG methylation can shed new light on the function of DNA methylation in modulating brain development and plasticity.

Neurogenesis precedes astrogenesis in embryonic brain development. Therefore, inhibiting the expression of genes critical for astrocytes in NSCs is a key step in determining the neuronal differentiation of these cells. DNMT1 is vital in the switch from neurogenesis to gliogenesis during this process. DNMT1 deficiency in neural progenitor cells (NPCs) leads to DNA hypomethylation and precocious astroglial differentiation through enhanced regulation of the Janus kinase-signal transducer and activator of transcription (JAK-STAT) signaling 
(Fan et al. 2005). The conditional knockout of DNMT1 in mitotic CNS precursor cells via the Cre/loxP system resulted in extensive hypomethylation in daughter cells, and these daughter cells were rapidly depleted within 3 weeks of postnatal life. In contrast, the inactivation of DNMT1 in postmitotic neurons did not affect the levels of global DNA methylation and cell survival during postnatal life (Fan et al. 2001). Therefore, appropriate DNA methylation status is essential for both the maintenance and differentiation of NSCs during early development. A recent study in mouse embryonic fibroblasts has showed that DNMT1 expression positively correlates with the cell proliferation rate, largely depending on the length of G1 phase, to prevent passive DNA demethylation. When the function of DNMT1 was inhibited and the proliferation was accelerated, passive DNA demethylation on the promoters of pluripotency-related genes, including Oct4, Nanog, Sox2, Esrrb, Cdh1, and Epcam, accumulated, which resulted in the upregulation of pluripotencyrelated gene expression (He et al. 2017). The "stemness" or the self-renewal property of NSCs is associated with a cohort of pluripotency-promoting transcription factors, whereas their differentiation is related to neurogenic and gliogenic genes. As demonstrated in the study mentioned above, the inheritance of DNA methylation mediated by DNMT1 may participate in the regulation of the expression of genes relating to proliferation or differentiation, thus favoring or prohibiting certain cell fates of NSCs. This requires further studies.

Several studies have revealed a critical role for de novo DNA methyltransferase DNMT3A in regulating NSC proliferation and differentiation. DNMT3A knockout mice exhibit enhanced self-renewal of NSCs and impaired neuronal differentiation for postnatal neurogenesis (Wu et al. 2010). Mechanistically, DNMT3A-mediated proximal promoter DNA methylation and nonpromoter DNA methylation are essential for regulating proliferation and neurogenesis-related genes expression, respectively (Wu et al. 2010). Additionally, an in vitro study revealed that DNMT3A deficiency led to increased cell proliferation as well as precocious astrocyte and oligodendrocyte differentiation of NSCs (Wu et al. 2012). Behaviorally, mice with conditional knockout of DNMT3A in GABAergic inhibitory neurons displayed several symptoms including impaired learning and memory (Lavery et al. 2020), which is tightly associated with adult hippocampal neurogenesis (Ming and Song 2005). Global loss of $\mathrm{mCpH}$ induced by DNMT3A deficiency resulted in altered gene expression in striatum inhibitory neurons (Lavery et al. 2020). It is well known that GABA-releasing interneurons are an important component of the adult NSC niche (Bond et al. 2015). Whether DNMT3A deletion in inhibitory neurons regulates adult neurogenesis in a cell non-autonomous manner requires clarification.

\section{Methyl-CpG-binding proteins}

DNA methylation exerts its biological function in at least two ways, i.e., by directly impeding the binding of transcriptional factors to gene promoter regions and by forming silenced states of chromatin via recruiting specialized transcription factors, namely methyl-CpG-binding proteins (MBPs) (Zou et al. 2012). There are three subgroups in the MBP family, including methyl-binding domain (MBD) proteins, zinc finger/Kaiso family proteins, and SET- and RING-associated (SRA) domain proteins (Jobe and Zhao 2017).

\section{Methyl-binding domain family}

The MBD family proteins include MBD1-5 and MeCP2 (methyl-CpG-binding protein 2) (Hsieh and Zhao 2016). Among these, MBD1 and MeCP2 have been comprehensively studied in the regulation of NSCs. Recent studies have showed that MBD1 is expressed in the NSCs of dentate gyrus in the adult hippocampus, and that MBD1 deficiency results in the accumulation of NSCs and the impairment of the neuronal lineage differentiation. Furthermore, transcriptome analysis showed that the MBD1 mutant causes the upregulation of genes related to cell differentiation, particularly those related to astrocyte lineage differentiation (Jobe et al. 2017). Additionally, MBD1 regulates NSC proliferation by directly binding to the promoter region of the basic fibroblast growth factor (bFGF), a potent mitogen for adult NSCs both in vitro and in vivo (Gokul et al. 2009), resulting in the tight regulation of bFGF expression in neural stem/progenitor cells (NSPCs) (Li et al. 2008). These studies reveal the important function of MBD1 in stem cell maintenance, thereby providing novel insights into how DNA methylation preserves the multipotency of stem cells for subsequent differentiation. Thus, the intrinsic epigenetic mechanisms mediated by MBD1 play crucial roles in the modulation of proliferation and differentiation of NSCs.

$\mathrm{MeCP} 2$, whose mutation causes the neurological disorder Rett syndrome, is another major regulator of gene expression belonging to the MBD family. As MeCP2 shows increased expression with neuronal differentiation (Jung et al. 2003), MeCP2 controls neuronal maturation and dendritic arborization in both developing (Kishi and Macklis 2010) and adult brains (Smrt et al. 2007). One of its best known targets is the brain-derived neurotrophic factor (BDNF), a neurotrophic factor that facilitates the differentiation, maturation, and survival of neurons in the mammalian brain (Bathina and Das 2015). Studies have showed that MeCP2 suppresses $B D N F$ gene expression by selectively binding to the BDNF promoter III. After neuronal activation and membrane depolarization, MeCP2 moves out of its binding site in the BDNF promoter, thus allowing transcription 
to proceed (Chen et al. 2003). Additionally, BDNF upregulation after neuronal activity involves the dissociation of the MeCP2-histone deacetylase-mSin3A repression complex from its promoter (Martinowich et al. 2003). Except for the regulation of neuronal maturation by MeCP2, a recent study has showed that MeCP2 plays a novel role in modulating the proliferation and differentiation of adult NSCs (aNSCs) in vivo and in vitro by epigenetically regulating the expression of miRNA, miR-137 (Szulwach et al. 2010). However, it is not clear whether MeCP2 could regulate other miRNAs. It is well established that MeCP2 interacts with $\mathrm{mCpG}$ through MBD to recruit a co-repressor complex (including histone deacetylases, transcriptional repressor $\mathrm{mSin} 3 \mathrm{~A}$, and other chromatin-silencing factors) (Nan et al. 1998), linking with its transcriptional repression domain (TRD), thereby altering chromatin organization and preventing transcription (Jones et al. 1998; Skene et al. 2010; Nan et al. 1996). Except for the primary function of gene silencing, recent studies demonstrate that $\mathrm{MeCP} 2$ binds to $5-\mathrm{hmC}$, an oxidation product of 5$\mathrm{mC}$, to facilitate transcription in the brain (Mellen et al. 2012). In accordance with the unexpected role of $\mathrm{MeCP} 2$, several studies have revealed that MeCP2 is a gene activator (Yasui et al. 2007; Chahrour et al. 2008) with critical roles in transcriptional regulation in the mammalian brain. Most MeCP2-bound promoters are actively expressed in human SH-SY5Y neurons (Yasui et al. 2007). Additionally, gene expression studies performed in the mouse hypothalamus suggested that MeCP2 associated with the coactivator CREB1 (cyclic AMP-responsive element-binding protein 1) for transcriptional activation (Chahrour et al. 2008). In addition to binding $\mathrm{mCpG}$ and $5-\mathrm{hmC}$, recent data showed that $\mathrm{MeCP} 2$ can bind $\mathrm{mCpH}$ in neurons in vivo (Chen et al. 2015) and repress transcription in vitro (Guo et al. 2014). Furthermore, the $\mathrm{mCpH}$ binding sites for $\mathrm{MeCP} 2$ are mostly restricted to $\mathrm{mCpApC}$ and the repressive transcriptional regulation in the brain is tuned by $\mathrm{MeCP} 2$ binding at $\mathrm{mCpG}$ and $\mathrm{mCpApC}$ sites (Lagger et al. 2017). As a multifunctional epigenetic reader, it has become evident that MeCP2 is involved in higher order chromatin organization (Dhasarathy and Wade 2008). Chromatin compaction by $\mathrm{MeCP} 2$ and nucleosomal arrays can be abolished by R168X and R270X Rett syndrome (RTT)-causing MeCP2 mutations (Georgel et al. 2003). In addition, the MeCP2-mediated heterochromatin organization and chromatin loops are critical for transcriptional regulation in the brain, which becomes aberrant because of RTT-inducing MeCP2 mutations (Horike et al. 2005; Agarwal et al. 2011). Overall, several questions on how MeCP2 and other MBDs regulate the proliferation and fate choice of NSCs remain unanswered.

\section{Zinc finger/Kaiso family}

The zinc finger/Kaiso family includes three members, namely Kaiso/ZBTB33, ZBTB4, and ZBTB38, and have been shown to preferentially or specifically bind methylated DNA through three Krüppel-like $\mathrm{C} 2 \mathrm{H} 2$ zinc fingers (Filion et al. 2006). Kaiso modulates transcription by binding to the methylated sequence $\mathrm{mCpGmCpG}$. Moreover, it can also bind the nonmethylated sequence CTGCNA, the consensus Kaiso binding site. The ZBTB4 and ZBTB38 require only a single methylated $C P G$ for binding. However, studies on the role of the Kaiso family in the regulation of brain development are limited. Kaisodeficient mice were found to be viable and fertile, without any developmental defects or abnormal gene expression (Prokhortchouk et al. 2006). Both ZBTB4 and ZBTB38 exhibited high expression in the brain (Filion et al. 2006). Thus, further studies on whether and how these proteins regulate NSCs are needed.

\section{SET- and RING-associated domain family}

Ubiquitin-like containing PHD ring finger (UHRF) 1 and UHRF2 are two members of the SRA domain family. They prefer to bind hemimethylated DNA using their SRA domain and interact with other epigenetic factors, such as histone deacetylase 1 (HDAC1) and DNMT1 (Bronner et al. 2013; Unoki et al. 2004). UHRF1 (also known as Np95 or ICBP90) is critical for the maintenance of DNA methylation through cell division and is also involved in DNA damage repair. Recently, an intriguing study developed a new method for studying the dynamic DNA methylation maintenance process - Hammer-seq sequencing technology, and found that UHRF1-Ligase1 and PCNA-DNMT1 interactions contribute to rapid replication-coupled maintenance, whereas the UHRF1-H3K9me2/3 interaction and nucleosome occupancy specifically regulate replicationuncoupled maintenance during mitotic inheritance of methylation (Ming et al. 2020). However, these two methylation maintenance pathways are imperfect, leading to the gradual loss of methylation at some CpG sites during continuous mitosis, which may be an important mechanism for selective hypomethylation in aging and tumorigenesis (Ming et al. 2020). UHRF2, also known as Np97 or NIRF, is involved in cell cycle progression. A study investigating the expression pattern of UHRF1 in the mouse brain from developmental to adult stages has showed that UHRF1 is abundantly expressed in proliferative NSPCs during the developmental stage and in the hippocampus of adult brain (Murao et al. 2014). 
However, how UHRF1 functions in NSPC proliferation and differentiation warrants further research.

\section{DNA demethylation in NSC proliferation and differentiation}

DNMTs are known as "writers" of DNA methylation, whereas MBPs are the "interpreters" of DNA methylation. What are the eraser proteins for DNA methylation? Cytosine demethylation can occur through a passive process, which takes place in the absence of functional DNMT1 activity during DNA replication (Ooi et al. 2009; Chen and Riggs 2011). A recent study has suggested that Gadd45 proteins couple with the DNAexcision-repair-based DNA demethylation mechanism to promote active DNA demethylation (Ma et al. 2009a). An activity-dependent immediate early gene Gadd45b, a member of the Gadd45 family, is required for the activity-induced DNA demethylation of specific gene promoters, which are crucial for adult neurogenesis, including BDNF and bFGF (Ma et al. 2009b). Correspondingly, Gadd45b knockout impaired the neural activityinduced proliferation of neural progenitors and the dendritic growth of newborn neurons in the adult hippocampus (Ma et al. 2009b).

In addition, DNA demethylation can occur actively via the enzymatic conversion of the methylated cytosine into cytosine without DNA replication. One well-known pathway of active demethylation is regulated by the TET family proteins, which catalyze 5 - $\mathrm{mC}$ into an oxidized 5$\mathrm{hmC}$ and subsequently into $5-\mathrm{fC}$ and $5-\mathrm{caC}$ (Tahiliani et al. 2009; Ito et al. 2010). TET family proteins have three members, namely TET1, TET2, and TET3, whose expression patterns differ in tissues. Interestingly, they are all expressed in the brain, with TET3 showing the highest level, followed by TET2 and TET1 (Szwagierczak et al. 2010). Correspondingly, the mammalian brain retains the highest concentration of 5 -hmC, the oxidation derivatives of 5 - $\mathrm{mC}$ by TET proteins. Therefore, TET enzymes play an important role in the regulation of NSCs in theory. A recent study has demonstrated that TET1 is highly expressed in NPCs in adult hippocampus, and that TET1-knockout mice show reduced progenitor proliferation, thus resulting in impaired spatial learning and memory (Zhang et al. 2013). In contrast, TET1 deletion has no effect in mouse development (Dawlaty et al. 2011) and, in NPCs, impacted a cohort of genes, which were hypermethylated and downregulated, involved in progenitor proliferation (Zhang et al. 2013).

During neurodevelopment, the expression dynamics of three TET dioxygenases are different. A significant and specific increase in TET2 expression, accompanied by a dramatic increase in global 5-hmC level, was found in differentiated aNSCs compared with proliferating aNSCs. In contrast, TET2 ablation stimulated aNSC proliferation and inhibited their neuronal and glial differentiation both in vivo and in vitro. Mechanistically, TET2 binds to the transcription factor Foxo3a and regulates the expression of genes related to aNSC proliferation and differentiation ( $\mathrm{Li}$ et al. 2017). Thus, TET1 and TET2 possess distinct roles in the regulation of NSCs through different mechanisms. Another member of TET proteins TET3 is also critical in NPC maintenance and in the terminal differentiation of neurons ( $\mathrm{Li}$ et al. 2015). An intriguing report has suggested a novel non-catalytic role for TET3 in regulating NSC maintenance within the adult SVZ (Montalban-Loro et al. 2019). MontalbánLoro and colleagues discovered that TET3 directly binds to Snrpn, belonging to the Prader-Willi imprinted gene cluster, thus contributing to the transcriptional inactivation of the gene (Montalban-Loro et al. 2019). The interaction between TET DNA dioxygenases and other epigenetic regulators during neural development warrants further exploration.

\section{Mechanisms of opioids and vitamin C by TET1}

Opioids, known as addictive drugs, have been studied extensively in NSCs (Eisch et al. 2000; Zheng et al. 2013). Our previous study showed that morphine blocks the CPP (conditioned place preference) training-induced enhanced survival of newborn neurons with no effect on early neural progenitors in adult hippocampus (Zhang et al. 2016). Because the expression of opioid receptors in NSCs is very low (Hutchins et al. 2017), the mechanism underlying NSC regulation by opioids is largely unknown. Our recent study has showed that the opioids morphine and naloxone, which can penetrate membranes, facilitate NSC proliferation via a receptorindependent and TET1-dependent pathway (Liang et al. 2020). These two opioids bound to the TET1 protein via three key residues (1880-1882) and suppressed the DNA demethylation ability of TET1, resulting in the reduced proliferation of NSCs. These results are consistent with that of a previous study on TET1 null mice. Additionally, the receptor-independent functions of naloxone and morphine were not observed in TET1-knockout NSCs. Furthermore, when the expression of opioid receptors was increased during the late stage of NSC differentiation, morphine but not naloxone, inhibited the neuronal differentiation of NSCs via a traditional receptor-dependent and miR181a-Prox1-Notch-related pathway (Fig. 1) (Hansen et al. 2011; Xu et al. 2014). These results demonstrate a direct link between opioids and epigenetic regulation in NSCs, thereby expanding our understanding on the regulatory mechanism of opioids onto NSCs.

In contrast to the impact of naloxone and morphine, some small chemicals, such as ascorbic acid (AA), enhance the catalytic activity of TET enzymes 


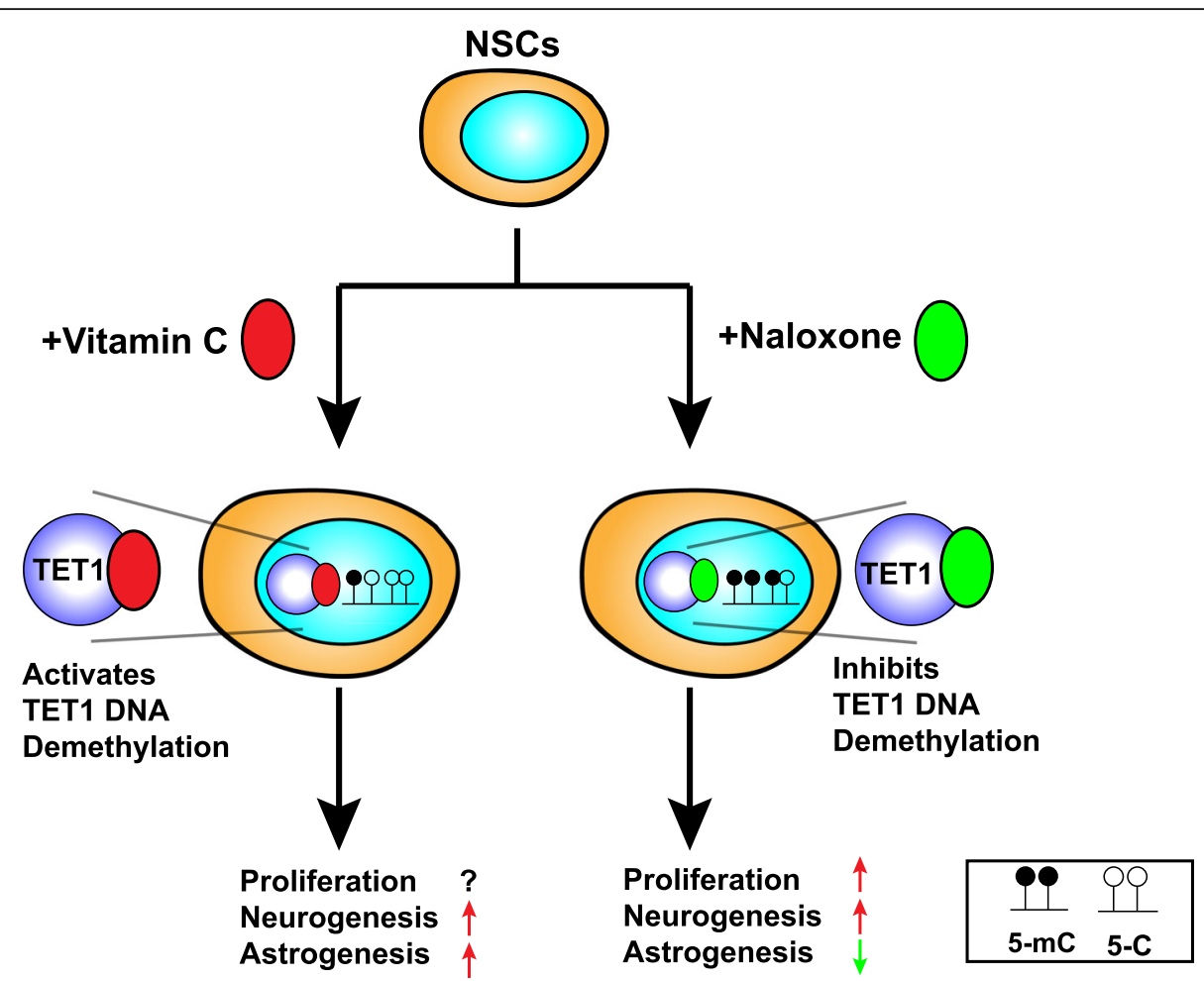

Fig. 1 Small molecules modulate NSCs by regulating TET1 activity. Vitamin C (Vc) increases the DNA demethylation activity of TET1 and increase both neurogenesis and astrogenesis of NSCS. Naloxone decreases the DNA demethylation activity of TET1, increases proliferation and neurogenesis of NSCs, and decreases astrogenesis

(Yin et al. 2013). AA (or vitamin C) can particularly bind to the catalytic domain of TET enzymes to enhance their oxidation capacity, leading to DNA demethylation. Thus, AA acts as a cofactor of TET enzymes (Yin et al. 2013). Emerging evidence demonstrates that AA-induced epigenetic regulation plays an important role in brain development. AA promoted the neuronal and astrocyte differentiation of CNS precursor cells in vitro (Lee et al. 2003). He and colleagues recently discovered that AA enhances NSC differentiation into dopamine (DA) neurons. Mechanistically, AA induced the TET1-mediated DNA hydroxymethylation on the promoters of DA phenotype gene. Subsequently, Nurr1, a transcription factor critical for DA neuron development, was recruited to these gene promoters, thereby activating transcription (He et al. 2015). The same research group then showed that AA treatment induces the enrichment of 5 -hmC near the consensus binding motifs of nuclear factor I (NFI) and enhanced the recruitment of NFI and STAT3 in the 5-hmC-enriched regions of astrocyte-specific genes, thereby leading to the upregulation of astrocytic genes and increased astrocyte differentiation (Kim et al. 2018) (Fig. 1). AA not only influences the catalytic activity of TET, but also plays a key role in determining the biological outcome of its function. In the presence of AA, TET1 negatively regulated somatic cell reprogramming by regulating 5$\mathrm{hmC}$ formation at MET-related loci, whereas in its absence, TET1 promoted MET-independent somatic cell reprogramming (Chen et al. 2013). These studies deepen our understanding of the essential functions of epigenetic regulation in linking external chemicals to the nuclear transcriptional control of gene expression in NSCs and their progeny. However, the interaction of AA with epigenetic pathways to regulate NSC proliferation remains unknown.

\section{Connections between DNMT1 and TET1}

We have thus far shown how DNA methylation and demethylation are closely linked. The connections between DNMT1 and TET1 have also been explored. DNMT1 preferentially recognizes hemimethylated DNA and remains activated in the $G_{1}$ phase, following $S$ and $M$ phases, to ensure that DNA methylation is stably inherited across generations (Law and Jacobsen 2010). On the other hand, TET1 has showed greater ability to demethylate hemimethylated $\mathrm{CpG}$ sites than methylated $\mathrm{CpG}$ sites (He et al. 2019) (Fig. 2a). Therefore, DNMT1 and TET1 compete with each other for the hemimethylated CpG sites (He et al. 2019). Furthermore, the tight competition between DNMT3s and TETs at a large 


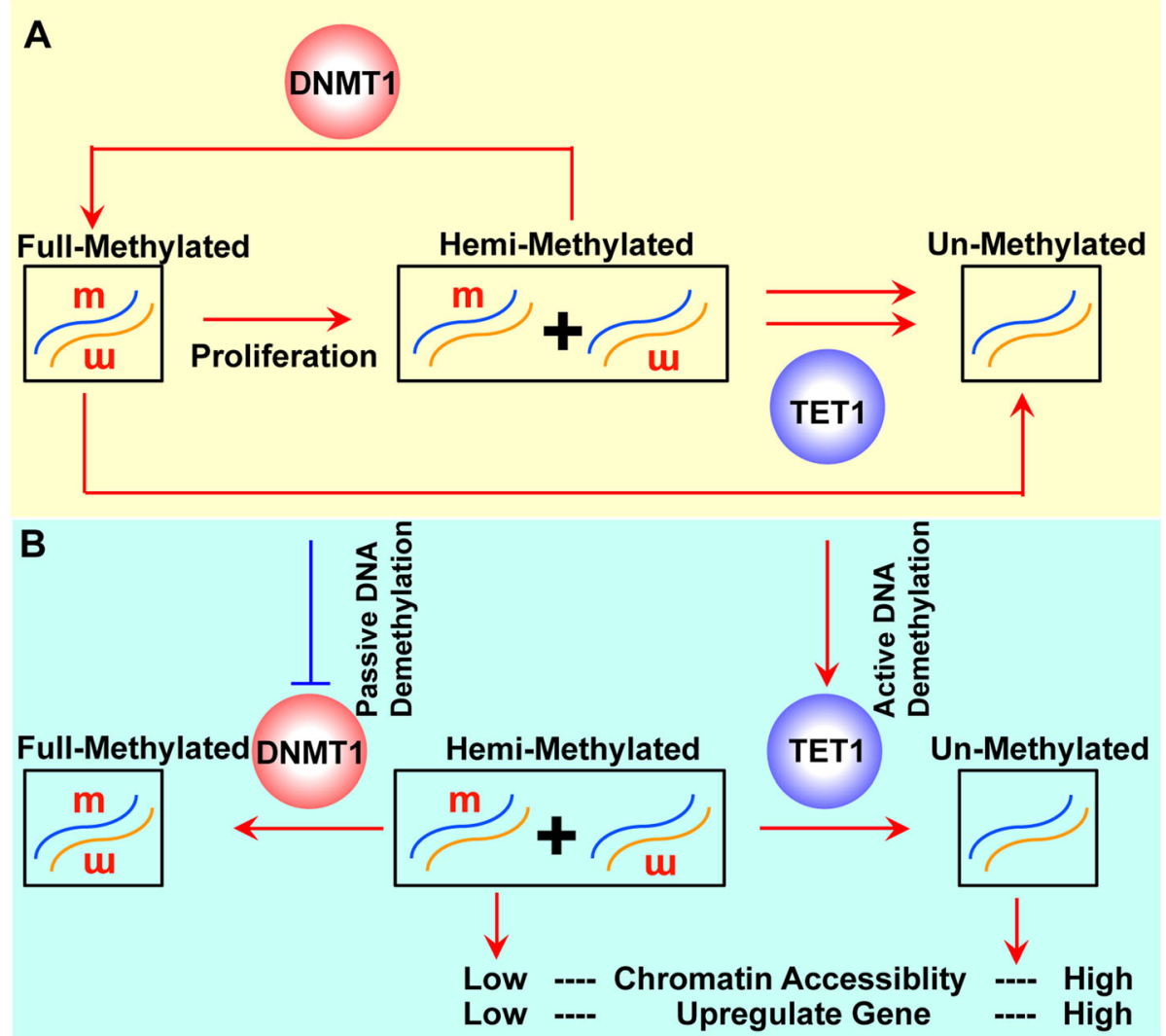

Fig. 2 The connections between DNMT1 and TET1. a DNMT1 maintains DNA methylation during proliferation by methylating hemimethylated CpG sites into full-methylated. TET1 has higher abilities to demethylate hemimethylated CpG sites than full-methylated. b Passive DNA demethylation by inhibiting DNMT1 leads to lower increase in chromatin accessibility and gene expression than active DNA demethylation by stimulating TET1

collection of methylated somatic enhancers is observed in both human and mouse pluripotent cells (Charlton et al. 2020).

Because the pluripotency-related and epithelial cellspecific genes are more likely to have unmethylated newly synthesized DNA strands after the $\mathrm{S}$ phase (He et al. 2017), the competition between DNMT1 and TET1 on these genes may play critical role in NSCs. This hypothesis is supported by three facts: 1) NSCs have high expression of several markers of pluripotency, such as Sox 2; 2) NSCs proliferate at a relatively high rate; and 3) the differentiation from NSCs to neurons and astrocytes involves changes in the expression of mesenchymal and epithelial markers.

DNA demethylation includes passive DNA demethylation, which is normally induced by inhibiting the functions of DNMT1, and active DNA demethylation, which is normally induced by stimulating the functions of TETs. Although both kinds of DNA demethylation decrease methylation levels around the transcription start sites, passive DNA demethylation decreases fullymethylated CpG sites but increases hemimethylated
CpG sites, whereas active DNA demethylation decreases hemimethylated $\mathrm{CpG}$ sites and increases unmethylated CpG sites. Because these two kinds of DNA demethylation have different abilities to affect chromatin accessibility and gene expression (He et al. 2019), they may play distinct roles even when induced in the same system (Fig. 2b).

Additional connections between DNMT1 and TET1 should also be discussed when AA is used to control TET1 activity or cell proliferation, when the epithelialmesenchymal transition (EMT) or MET is induced, and when the switch between energy metabolic models (oxidative phosphorylation and glycolysis) is modulated (Sun et al. 2020).

\section{Abnormal DNA modifications and neurological diseases}

Emerging evidences have showed that abnormal DNA methylation is associated with the pathophysiology of many neurological diseases.

Several studies suggest that aberrant DNA methylation is involved in many neurodegenerative diseases, including 
Parkinson's disease (PD) and Alzheimer's disease (AD) (De Jager et al. 2014; Coppieters et al. 2014; Chuang et al. 2017). By new base-resolution mapping and analytical technologies, a study has identified a group of $\mathrm{AD}$-specific 5-mC, 5-hmC, and 5-fC/-caC signatures (Fetahu et al. 2019). In addition, DNA methylation and gene expression in schizophrenia, a severe psychiatric disease, have also been explored (Liu et al. 2014; Vitale et al. 2017). Five gene loci which are differentially methylated are common in different cell types deriving from schizophrenia patient. Collectively, these studies demonstrate that DNA methylation plays a pivotal role in neurological diseases and that the identified disease-specific epigenetic signatures can be implicated in the early diagnosis and prognosis of the diseases.

DNMT1 mutations lead to central and peripheral neurodegeneration. Thus, the patients present hereditary sensory and autonomic neuropathy with dementia and hearing loss, which arise from global hypomethylation and site-specific hypermethylation (Klein et al. 2011). In addition, mutations in DNMT3A have recently been associated with neurodevelopmental disorders. Through whole-genome sequencing, DNMT3A has been identified as a candidate gene marker for autism spectrum disorder (Jiang et al. 2013), and mutations in DNMT3A have been involved in overgrowth syndrome (TattonBrown et al. 2014; Tatton-Brown et al. 2018) and acute monocytic leukemia (Yan et al. 2011). In contrast, de novo missense mutations in the PWWP domain of DNMT3A result in microcephalic dwarfism due to failure of binding to H3K36me2 and H3K36me3, thereby altering DNA methylation of Polycomb-marked regions (Heyn et al. 2019). Thus, these findings provide a novel framework for the study of neurological disorders.

MeCP2 dysfunction, including loss of function and increased dosage, causes a range of neuropsychiatric disorders (Moretti and Zoghbi 2006). Numerous studies have shown that RTT, a neurodevelopmental disorder, is closely related to mutation of $\mathrm{MeCP} 2$ on the $\mathrm{X}$ chromosome (Moretti and Zoghbi 2006; Amir et al. 1999; Weaving et al. 2005). A large amount of data has revealed that reduced $5-\mathrm{mC}$ binding by $\mathrm{MeCP} 2$ mutations in the MBD contributes to the pathophysiology of RTT (Agarwal et al. 2011; Kudo et al. 2003). Additionally, a recent study demonstrated that MeCP2 R133C mutation may cause the disease by inhibiting 5 -hmC binding (Mellen et al. 2012). Moreover, in mouse models of RTT and MeCP2 duplication syndrome, transcriptional analysis revealed that MeCP2 null or duplication affected genes with higher $\mathrm{MeCP} 2$ binding and $\mathrm{mCpH}$ levels accumulating as neurons maturation, which may be the molecular mechanism for the delayed onset of Rett (Chen et al. 2015). Furthermore, RTT-inducing mutants failed to induce MeCP2-driven chromatin compaction
(Nikitina et al. 2007). Until recently, a new view on how the mutation of this gene causes the occurrence and development of RTT has emerged. The latest discovery from Young et al. revealed that methylated DNA significantly promoted the phase separation of $\mathrm{MeCP} 2$, which can be disrupted by RTT-causing mutated MECP2 and lead to changes in heterochromatin formation and abnormal transcription of related genes, ultimately resulting in the occurrence of diseases ( $\mathrm{Li}$ et al. 2020). Two other earlier studies (Wang et al. 2020b; Fan et al. 2020) reported similar findings, showing that MeCP2-mediated phase separation is critical for the pathology of RTT, which provides a new angle to drug development for the treatment of neurological diseases. Mounting evidences show that malfunctioning TET proteins and abnormal 5-hmC modifications are involved in the pathophysiology of different neurological diseases. The selective deletion of TET1 in nucleus accumbens neurons in adult mice produced antidepressant-like effects (Feng et al. 2017). Genome-wide mapping revealed that 5-hmC levels are inversely correlated with MeCP2 dosage, whose mutations cause Rett syndrome (Szulwach et al. 2011). In addition, abnormal 5-hmC levels participate in the etiology of fragile $\mathrm{X}$-associated tremor/ataxia syndrome, a late-onset neurodegenerative disorder (Yao et al. 2014). Thus, further research on 5 -hmC modifications and TET proteins in the context of neurodevelopmental disorders is urgently needed. These studies will advance the understanding of diseases and contribute to the development of effective therapeutic treatments for human neurodevelopmental disorders.

\section{Conclusions}

Here, we reviewed recent studies on proteins involved in DNA methylation, focusing on the proliferation and differentiation of NSCs. We discussed the connection between DNMT1, which methylates hemimethylated CpG sites, and TET1, which demethylates cytosine, because these proteins are highly connected in the expression of pluripotency-related and EMT- or MET-related genes, as well as in the regulation of cell proliferation and energy metabolism, which have been demonstrated to play important roles in a variety of biological processes, including embryonic development, somatic cell reprogramming, and cancer progression. By using these two proteins and DNA methylation regulation as bridges, the newly explored mechanisms in these processes can be further the studies on the proliferation and differentiation of NSCs.

In addition, we have identified a TET1-dependent and receptor-independent pathway used by opioids, i.e., morphine and naloxone, to modulate the proliferation and differentiation of NSCs. The chronic or repetitive administration of opioids causes adverse side effects, 
including tolerance and addiction, which are highly associated with adult hippocampal neurogenesis and contextual learning (Eisch and Harburg 2006; Leuner et al. 2006). Opioid receptors and endogenous opioid peptides should be considered in future studies on DNA methylation and NSCs.

Increasing evidence suggests that DNMT3A and DNMT3B closely interact with H3K36 methylation through their PWWP domain to maintain the proper level of intergenic and intragenic DNA methylation, which plays critical roles in mammalian development and has been implicated in human developmental disorders and cancers. Two promising studies simultaneously revealed that DNMT3A was recruited to the H3K36me2-marked domain to regulate the establishment of intergenic DNA methylation (Xu et al. 2020; Weinberg et al. 2019). Aberrant levels of histone H3K36me2 lead to significant alterations in global 5-mC levels, which result from abnormal DNA hypermethylation by DNMT3A in the intergenic region (Xu et al. 2020). In contrast, missense-mutant (Y365C, I310N or W297del) DNMT3A in the PWWP domain, which causes Tatton-Brown-Rahman syndrome (TBRS), a childhood overgrowth disorder, abolishes its binding affinity towards H3K36me2 resulting in aberrant intergenic CpG methylation (Weinberg et al. 2019). Mice with DNMT3A carrying a D329A point mutation in the PWWP domain exhibit postnatal growth retardation. DNMT3A $^{\text {D329A }}$ is selectively recruited to H3K27me3marked chromatin, which leads to DNA hypermethylation in the H3K27me3-marked domain and derepression of genes involved in hypothalamus development (Sendzikaite et al. 2019). Similarly, a strong interaction between DNMT3B with H3K36me3 is observed both in mouse (Neri et al. 2017; Lee et al. 2017) and human embryonic stem cells (Lee et al. 2017; Tan et al. 2019), which is important for regulating cell typespecific genes expression as well as cancer establishment and progression. However, the function of crosstalk between DNMT3s and H3K36 methylations in NSC regulation has not been determined.

Glioblastoma multiforme (GBM) is a common brain tumor in children and adults. However, paediatric GBM is biologically and mechanistically distinct from adult GBM (Jones et al. 2012; Sturm et al. 2012). It has been shown that two recurrent mutations (K27M and G34R/ $\mathrm{V})$ in $H 3 F 3 A$ encoding histone $\mathrm{H} 3$ variant $\mathrm{H} 3.3$ are closely associated with numerous pediatric brain tumors (Schwartzentruber et al. 2012). Recently, global analysis of histone modifications revealed that K27M mutation led to significantly reduced amounts of $\mathrm{H} 3 \mathrm{~K} 27 \mathrm{me} 2$ and H3K27me3 (Chan et al. 2013; Lewis et al. 2013). As discussed above, there is intense interaction of DNMT3s with histone modifications to regulate DNA methylation.
It is promising to investigate whether altered histone methylations induced by H3.3 onco-mutations lead to tumorigenesis by reshaping DNA methylation.

This review focused on the role of DNA methylation, including the related proteins and small molecules, in the modulation of proliferation and differentiation of NSCs. As a common epigenetic modification, DNA methylation is highly linked to other epigenetic modifications, including non-coding RNAs and histone modifications, as well as to a variety of biological processes. Understanding the interplay between DNA methylation and NSCs in a broad biological context can facilitate the related studies and reduce potential misunderstanding.

\begin{abstract}
Abbreviations
AA: Ascorbic acid; BDNF: Brain-derived neurotrophic factor; CNS: Central nervous system; CPP: Conditioned place preference; DA: Dopamine; EMT: Epithelial-mesenchymal transition; HDAC1: Histone deacetylase 1; JAKSTAT: Janus kinase-signal transducer and activator of transcription; MBD: Methyl-binding domain; MBP: Methyl-CpG-binding proteins; MET: Mesenchymal-epithelial transition; NFI: Nuclear factor l; NIRF: Np95/ ICBP90-like RING finger protein; NPCs: Neural progenitor cells; NSCs: Neural stem cells; SAM: S-adenosyl-I-methionine; SGZ: Subgranular zone; SRA: SETand RING-associated; SVZ: Subventricular zone; TET: Ten-eleven translocation
\end{abstract}

\section{Authors' contributions}

SJ, YJ, and MX wrote the paper; LHH, PD and $\mathrm{ZhH}$ revised the paper. All authors read and approved the final manuscript.

\section{Funding}

This work was supported by the Guangzhou Key Area Research and Development Project, No. 202007030003, the National Natural Science Foundation of China, No. U1601228, 81901288 and 31671475, the Strategic Priority Research Program of Chinese Academy of Sciences, No.

XDA16010305; the Natural Science Foundation of Guangdong Province, No. 2017A030313786; the Key Research Program of Frontier Sciences of Chinese Academy of Sciences, No. QYZDB-SSW-SMC031; the International Partnership Program of Chinese Academy of Sciences, No. 154144KYSB20190034; the Key Research \& Development Program of Guangzhou Regenerative Medicine and Health Guangdong Laboratory, No. 2018GZR110104008, and the Science and Technology Planning Project of Guangdong Province, No. 2017 B030314056.

\section{Competing interests}

The authors declare that they have no competing interests.

\section{Author details}

${ }^{1}$ Bioland Laboratory (Guangzhou Regenerative Medicine and Health Guangdong Laboratory), \#188 Kaiyuan Ave., Science City, Huangpu District, Guangzhou 510700, China. ${ }^{2}$ CAS Key Laboratory of Regenerative Biology, Guangzhou Institutes of Biomedicine and Health, Chinese Academy of Sciences, Guangzhou 510530, China. ${ }^{3}$ Guangdong Provincial Key Laboratory of Stem Cell and Regenerative Medicine, Guangzhou 510530, China. ${ }^{4}$ Institutes for Stem Cell and Regeneration, Chinese Academy of Sciences, Beijing 100101, China. ${ }^{5}$ School of Life Science, Westlake University, Hangzhou 310024, China.

Received: 25 July 2020 Accepted: 25 November 2020

Published online: 02 March 2021

\footnotetext{
References

Agarwal N, Becker A, Jost KL, Haase S, Thakur BK, Brero A, et al. MeCP2 Rett mutations affect large scale chromatin organization. Hum Mol Genet. 2011; 20:4187-95.

Amir RE, Van den Veyver IB, Wan M, Tran CQ, Francke U, Zoghbi HY. Rett syndrome is caused by mutations in X-linked MECP2, encoding methyl-CpGbinding protein 2. Nat Genet. 1999;23:185-8.
} 
Arand J, Spieler D, Karius T, Branco MR, Meilinger D, Meissner A, et al. In vivo control of $\mathrm{CpG}$ and non-CpG DNA methylation by DNA methyltransferases. PLoS Genet. 2012;8:e1002750.

Bathina S, Das UN. Brain-derived neurotrophic factor and its clinical implications. Arch Med Sci. 2015;11:1164-78.

Berg DA, Su Y, Jimenez-Cyrus D, Patel A, Huang N, Morizet D, et al. A common embryonic origin of stem cells drives developmental and adult neurogenesis. Cell. 2019;177:654-68 e15.

Bird A. Perceptions of epigenetics. Nature. 2007;447:396-8.

Bond AM, Ming GL, Song H. Adult mammalian neural stem cells and neurogenesis: five decades later. Cell Stem Cell. 2015;17:385-95.

Bronner C, Krifa M, Mousli M. Increasing role of UHRF1 in the reading and inheritance of the epigenetic code as well as in tumorogenesis. Biochem Pharmacol. 2013;86:1643-9.

Chahrour M, Jung SY, Shaw C, Zhou X, Wong ST, Qin J, et al. MeCP2, a key contributor to neurological disease, activates and represses transcription. Science. 2008;320:1224-9.

Chan KM, Fang D, Gan H, Hashizume R, Yu C, Schroeder M, et al. The histone H3. $3 \mathrm{~K} 27 \mathrm{M}$ mutation in pediatric glioma reprograms H3K27 methylation and gene expression. Genes Dev. 2013;27:985-90.

Charlton J, Jung EJ, Mattei AL, Bailly N, Liao J, Martin EJ, et al. TETs compete with DNMT3 activity in pluripotent cells at thousands of methylated somatic enhancers. Nat Genet. 2020;52:819-27.

Chen J, Guo L, Zhang L, Wu H, Yang J, Liu H, et al. Vitamin C modulates TET1 function during somatic cell reprogramming. Nat Genet. 2013:45:1504-9.

Chen L, Chen K, Lavery LA, Baker SA, Shaw CA, Li W, et al. MeCP2 binds to non-CG methylated DNA as neurons mature, influencing transcription and the timing of onset for Rett syndrome. Proc Natl Acad Sci U S A. 2015;112:5509-14.

Chen WG, Chang Q, Lin Y, Meissner A, West AE, Griffith EC, et al. Derepression of BDNF transcription involves calcium-dependent phosphorylation of MeCP2. Science. 2003;302:885-9.

Chen ZX, Riggs AD. DNA methylation and demethylation in mammals. J Biol Chem. 2011;286:18347-53.

Chuang YH, Paul KC, Bronstein JM, Bordelon Y, Horvath S, Ritz B. Parkinson's disease is associated with DNA methylation levels in human blood and saliva. Genome Med. 2017;9:76.

Coppieters N, Dieriks BV, Lill C, Faull RL, Curtis MA, Dragunow M. Global changes in DNA methylation and hydroxymethylation in Alzheimer's disease human brain. Neurobiol Aging. 2014;35:1334-44.

Dawlaty MM, Ganz K, Powell BE, Hu YC, Markoulaki S, Cheng AW, et al. Tet1 is dispensable for maintaining pluripotency and its loss is compatible with embryonic and postnatal development. Cell Stem Cell. 2011;9:166-75.

De Jager PL, Srivastava G, Lunnon K, Burgess J, Schalkwyk LC, Yu L, et al. Alzheimer's disease: early alterations in brain DNA methylation at ANK1, BIN1, RHBDF2 and other loci. Nat Neurosci. 2014;17:1156-63.

Dhasarathy A, Wade PA. The MBD protein family-reading an epigenetic mark? Mutat Res. 2008;647:39-43.

Eisch AJ, Barrot M, Schad CA, Self DW, Nestler EJ. Opiates inhibit neurogenesis in the adult rat hippocampus. Proc Natl Acad Sci U S A. 2000;97:7579-84.

Eisch AJ, Harburg GC. Opiates, psychostimulants, and adult hippocampal neurogenesis: insights for addiction and stem cell biology. Hippocampus. 2006;16:271-86.

Fan C, Zhang H, Fu L, Li Y, Du Y, Qiu Z, et al. Rett mutations attenuate phase separation of MeCP2. Cell Discov. 2020;6:38.

Fan G, Beard C, Chen RZ, Csankovszki G, Sun Y, Siniaia M, et al. DNA hypomethylation perturbs the function and survival of CNS neurons in postnatal animals. J Neurosci. 2001;21:788-97.

Fan G, Martinowich K, Chin MH, He F, Fouse SD, Hutnick L, et al. DNA methylation controls the timing of astrogliogenesis through regulation of JAK-STAT signaling. Development. 2005;132:3345-56.

Feng J, Pena CJ, Purushothaman I, Engmann O, Walker D, Brown AN, et al. Tet1 in nucleus Accumbens opposes depression- and anxiety-like behaviors. Neuropsychopharmacology. 2017:42:1657-69.

Fetahu IS, Ma D, Rabidou K, Argueta C, Smith M, Liu H, et al. Epigenetic signatures of methylated DNA cytosine in Alzheimer's disease. Sci Adv. 2019; 5:eaaw2880.

Filion GJ, Zhenilo S, Salozhin S, Yamada D, Prokhortchouk E, Defossez PA. A family of human zinc finger proteins that bind methylated DNA and repress transcription. Mol Cell Biol. 2006;26:169-81.

Georgel PT, Horowitz-Scherer RA, Adkins N, Woodcock CL, Wade PA, Hansen JC. Chromatin compaction by human MeCP2. Assembly of novel secondary chromatin structures in the absence of DNA methylation. J Biol Chem. 2003; 278:32181-8.

Globisch D, Munzel M, Muller M, Michalakis S, Wagner M, Koch S, et al. Tissue distribution of 5-hydroxymethylcytosine and search for active demethylation intermediates. PLoS One. 2010;5:e15367.

Gokul G, Ramakrishna G, Khosla S. Reprogramming of HeLa cells upon DNMT3L overexpression mimics carcinogenesis. Epigenetics. 2009;4:322-9.

Goll MG, Bestor TH. Eukaryotic cytosine methyltransferases. Annu Rev Biochem. 2005;74:481-514

Guo JU, Su Y, Shin JH, Shin J, Li H, Xie B, et al. Distribution, recognition and regulation of non-CpG methylation in the adult mammalian brain. Nat Neurosci. 2014;17:215-22.

Hansen JC, Wexler BB, Rogers DJ, Hite KC, Panchenko T, Ajith S, et al. DNA binding restricts the intrinsic conformational flexibility of methyl CpG binding protein 2 (MeCP2). J Biol Chem. 2011;286:18938-48.

He S, Sun H, Lin L, Zhang Y, Chen J, Liang L, et al. Passive DNA demethylation preferentially up-regulates pluripotency-related genes and facilitates the generation of induced pluripotent stem cells. J Biol Chem. 2017;292:1854255.

He S, Wang F, Zhang Y, Chen J, Liang L, Li Y, et al. Hemi-methylated CpG sites connect Dnmt1-knockdown-induced and Tet1-induced DNA demethylation during somatic cell reprogramming. Cell Discov. 2019;5:11.

He XB, Kim M, Kim SY, Yi SH, Rhee YH, Kim T, et al. Vitamin C facilitates dopamine neuron differentiation in fetal midbrain through TET1- and JMJD3-dependent epigenetic control manner. Stem Cells. 2015;33:1320-32.

Heyn P, Logan CV, Fluteau A, Challis RC, Auchynnikava T, Martin CA, et al. Gainof-function DNMT3A mutations cause microcephalic dwarfism and hypermethylation of Polycomb-regulated regions. Nat Genet. 2019;51:96-105.

Horike S, Cai S, Miyano M, Cheng JF, Kohwi-Shigematsu T. Loss of silentchromatin looping and impaired imprinting of DLX5 in Rett syndrome. Nat Genet. 2005;37:31-40.

Hsieh J, Zhao X. Genetics and epigenetics in adult neurogenesis. Cold Spring Harb Perspect Biol. 2016;8:a018911.

Hutchins AP, Yang Z, Li Y, He F, Fu X, Wang X, et al. Models of global gene expression define major domains of cell type and tissue identity. Nucleic Acids Res. 2017:45:2354-67.

Ito S, D'Alessio AC, Taranova OV, Hong K, Sowers LC, Zhang Y. Role of Tet proteins in $5 \mathrm{mC}$ to $5 \mathrm{hmC}$ conversion, ES-cell self-renewal and inner cell mass specification. Nature. 2010;466:1129-33.

Ito S, Shen L, Dai Q, Wu SC, Collins LB, Swenberg JA, et al. Tet proteins can convert 5-methylcytosine to 5-formylcytosine and 5-carboxylcytosine. Science. 2011;333:1300-3.

Jaenisch R, Bird A. Epigenetic regulation of gene expression: how the genome integrates intrinsic and environmental signals. Nat Genet. 2003;33(Suppl): 245-54.

Jiang YH, Yuen RK, Jin X, Wang M, Chen N, Wu X, et al. Detection of clinically relevant genetic variants in autism spectrum disorder by whole-genome sequencing. Am J Hum Genet. 2013;93:249-63.

Jobe EM, Gao Y, Eisinger BE, Mladucky JK, Giuliani CC, Kelnhofer LE, et al. MethylCpG-binding protein MBD1 regulates neuronal lineage commitment through maintaining adult neural stem cell identity. J Neurosci. 2017;37:523-36.

Jobe EM, Zhao X. DNA methylation and adult neurogenesis. Brain Plast. 2017;3:5-26.

Jones C, Perryman L, Hargrave D. Paediatric and adult malignant glioma: close relatives or distant cousins? Nat Rev Clin Oncol. 2012;9:400-13.

Jones PL, Veenstra GJ, Wade PA, Vermaak D, Kass SU, Landsberger N, et al. Methylated DNA and MeCP2 recruit histone deacetylase to repress transcription. Nat Genet. 1998;19:187-91.

Jung BP, Jugloff DG, Zhang G, Logan R, Brown S, Eubanks JH. The expression of methyl CpG binding factor MeCP2 correlates with cellular differentiation in the developing rat brain and in cultured cells. J Neurobiol. 2003;55:86-96.

Kempermann G, Gage FH. New nerve cells for the adult brain. Sci Am. 1999;280: 48-53.

Kim JH, Kim M, He XB, Wulansari N, Yoon BH, Bae DH, et al. Vitamin C promotes astrocyte differentiation through DNA Hydroxymethylation. Stem Cells. 2018; 36:1578-88.

Kishi N, Macklis JD. MeCP2 functions largely cell-autonomously, but also non-cellautonomously, in neuronal maturation and dendritic arborization of cortical pyramidal neurons. Exp Neurol. 2010;222:51-8.

Klein CJ, Botuyan MV, Wu Y, Ward CJ, Nicholson GA, Hammans S, et al. Mutations in DNMT1 cause hereditary sensory neuropathy with dementia and hearing loss. Nat Genet. 2011;43:595-600. 
Kriaucionis S, Heintz N. The nuclear DNA base 5-hydroxymethylcytosine is present in Purkinje neurons and the brain. Science. 2009;324:929-30.

Kriegstein A, Alvarez-Buylla A. The glial nature of embryonic and adult neural stem cells. Annu Rev Neurosci. 2009;32:149-84.

Kudo S, Nomura Y, Segawa M, Fujita N, Nakao M, Schanen C, et al. Heterogeneity in residual function of $\mathrm{MeCP} 2$ carrying missense mutations in the methyl CpG binding domain. J Med Genet. 2003;40:487-93.

Lagger S, Connelly JC, Schweikert G, Webb S, Selfridge J, Ramsahoye BH, et al. $\mathrm{MeCP} 2$ recognizes cytosine methylated tri-nucleotide and di-nucleotide sequences to tune transcription in the mammalian brain. PLoS Genet. 2017; 13:e1006793.

Lavery LA, Ure K, Wan YW, Luo C, Trostle AJ, Wang W, et al. Losing Dnmt3a dependent methylation in inhibitory neurons impairs neural function by a mechanism impacting Rett syndrome. Elife. 2020;9:e52981.

Law JA, Jacobsen SE. Establishing, maintaining and modifying DNA methylation patterns in plants and animals. Nat Rev Genet. 2010;11:204-20.

Lee JH, Park SJ, Nakai K. Differential landscape of non-CpG methylation in embryonic stem cells and neurons caused by DNMT3s. Sci Rep. 2017;7:11295.

Lee JY, Chang MY, Park CH, Kim HY, Kim JH, Son H, et al. Ascorbate-induced differentiation of embryonic cortical precursors into neurons and astrocytes. J Neurosci Res. 2003;73:156-65.

Leuner B, Gould E, Shors TJ. Is there a link between adult neurogenesis and learning? Hippocampus. 2006;16:216-24.

Lewis PW, Muller MM, Koletsky MS, Cordero F, Lin S, Banaszynski LA, et al. Inhibition of PRC2 activity by a gain-of-function $\mathrm{H} 3$ mutation found in pediatric glioblastoma. Science. 2013;340:857-61.

Li CH, Coffey EL, Dall'Agnese A, Hannett NM, Tang X, Henninger JE, et al. MeCP2 links heterochromatin condensates and neurodevelopmental disease. Nature. 2020;586:440-4

Li T, Yang D, Li J, Tang Y, Yang J, Le W. Critical role of Tet3 in neural progenitor cell maintenance and terminal differentiation. Mol Neurobiol. 2015:51:142-54.

Li X, Barkho BZ, Luo Y, Smrt RD, Santistevan NJ, Liu C, et al. Epigenetic regulation of the stem cell mitogen Fgf-2 by Mbd1 in adult neural stem/progenitor cells. J Biol Chem. 2008;283:27644-52.

Li X, Yao B, Chen L, Kang Y, Li Y, Cheng Y, et al. Ten-eleven translocation 2 interacts with forkhead box $\mathrm{O} 3$ and regulates adult neurogenesis. Nat Commun. 2017:8:15903.

Li Y, Zhang Z, Chen J, Liu W, Lai W, Liu B, et al. Stella safeguards the oocyte methylome by preventing de novo methylation mediated by DNMT1. Nature. 2018;564:136-40.

Liang L, Chen J, Li Y, Lai X, Sun H, Li C, et al. Morphine and naloxone facilitate neural stem cells proliferation via a TET1-dependent and receptorindependent pathway. Cell Rep. 2020;30:3625-31 e6.

Lister R, Mukamel EA, Nery JR, Urich M, Puddifoot CA, Johnson ND, et al. Global epigenomic reconfiguration during mammalian brain development. Science. 2013:341:1237905.

Lister R, Pelizzola M, Dowen RH, Hawkins RD, Hon G, Tonti-Filippini J, et al. Human DNA methylomes at base resolution show widespread epigenomic differences. Nature. 2009;462:315-22.

Liu J, Chen J, Ehrlich S, Walton E, White T, Perrone-Bizzozero N, et al. Methylation patterns in whole blood correlate with symptoms in schizophrenia patients. Schizophr Bull. 2014;40:769-76.

Ma DK, Guo JU, Ming GL, Song H. DNA excision repair proteins and Gadd45 as molecular players for active DNA demethylation. Cell Cycle. 2009a;8:1526-31.

Ma DK, Jang MH, Guo JU, Kitabatake Y, Chang ML, Pow-Anpongkul N, et al. Neuronal activity-induced Gadd45b promotes epigenetic DNA demethylation and adult neurogenesis. Science. 2009b;323:1074-7.

Martinowich K, Hattori D, Wu H, Fouse S, He F, Hu Y, et al. DNA methylationrelated chromatin remodeling in activity-dependent BDNF gene regulation. Science. 2003;302:890-3.

Mellen M, Ayata P, Dewell S, Kriaucionis S, Heintz N. MeCP2 binds to 5hmC enriched within active genes and accessible chromatin in the nervous system. Cell. 2012;151:1417-30.

Ming $\mathrm{GL}$, Song $\mathrm{H}$. Adult neurogenesis in the mammalian central nervous system. Annu Rev Neurosci. 2005;28:223-50.

Ming $\mathrm{GL}$, Song $\mathrm{H}$. Adult neurogenesis in the mammalian brain: significant answers and significant questions. Neuron. 2011;70:687-702.

Ming X, Zhang Z, Zou Z, Lv C, Dong Q, He Q, et al. Kinetics and mechanisms of mitotic inheritance of DNA methylation and their roles in aging-associated methylome deterioration. Cell Res. 2020;30:980-96.
Montalban-Loro R, Lozano-Urena A, Ito M, Krueger C, Reik W, Ferguson-Smith AC, et al. TET3 prevents terminal differentiation of adult NSCs by a non-catalytic action at Snrpn. Nat Commun. 2019;10:1726.

Moretti P, Zoghbi HY. MeCP2 dysfunction in Rett syndrome and related disorders. Curr Opin Genet Dev. 2006;16:276-81.

Murao N, Matsuda T, Noguchi H, Koseki H, Namihira M, Nakashima K. Characterization of Np95 expression in mouse brain from embryo to adult: A novel marker for proliferating neural stem/precursor cells. Neurogenesis (Austin). 2014;1:e976026.

Nan X, Ng HH, Johnson CA, Laherty CD, Turner BM, Eisenman RN, et al. Transcriptional repression by the methyl-CpG-binding protein MeCP2 involves a histone deacetylase complex. Nature. 1998;393:386-9.

Nan X, Tate P, Li E, Bird A. DNA methylation specifies chromosomal localization of MeCP2. Mol Cell Biol. 1996;16:414-21.

Neri F, Rapelli S, Krepelova A, Incarnato D, Parlato C, Basile G, et al. Intragenic DNA methylation prevents spurious transcription initiation. Nature. 2017;543:72-7.

Nikitina T, Shi X, Ghosh RP, Horowitz-Scherer RA, Hansen JC, Woodcock CL. Multiple modes of interaction between the methylated DNA binding protein MeCP2 and chromatin. Mol Cell Biol. 2007;27:864-77.

Okano M, Xie S, Li E. Cloning and characterization of a family of novel mammalian DNA (cytosine-5) methyltransferases. Nat Genet. 1998;19:219-20.

Ooi SK, O'Donnell AH, Bestor TH. Mammalian cytosine methylation at a glance. J Cell Sci. 2009;122:2787-91.

Pastor WA, Aravind L, Rao A. TETonic shift: biological roles of TET proteins in DNA demethylation and transcription. Nat Rev Mol Cell Biol. 2013;14:341-56.

Prokhortchouk A, Sansom O, Selfridge J, Caballero IM, Salozhin S, Aithozhina D, et al. Kaiso-deficient mice show resistance to intestinal cancer. Mol Cell Biol. 2006;26:199-208.

Ramsahoye BH, Biniszkiewicz D, Lyko F, Clark V, Bird AP, Jaenisch R. Non-CpG methylation is prevalent in embryonic stem cells and may be mediated by DNA methyltransferase 3a. Proc Natl Acad Sci U S A. 2000;97:5237-42.

Reik W. Stability and flexibility of epigenetic gene regulation in mammalian development. Nature. 2007;447:425-32.

Schwartzentruber J, Korshunov A, Liu XY, Jones DT, Pfaff E, Jacob K, et al. Driver mutations in histone $\mathrm{H} 3.3$ and chromatin remodelling genes in paediatric glioblastoma. Nature. 2012;482:226-31.

Sendzikaite G, Hanna CW, Stewart-Morgan KR, Ivanova E, Kelsey G. A DNMT3A PWWP mutation leads to methylation of bivalent chromatin and growth retardation in mice. Nat Commun. 2019;10:1884.

Skene PJ, Illingworth RS, Webb S, Kerr AR, James KD, Turner DJ, et al. Neuronal $\mathrm{MeCP} 2$ is expressed at near histone-octamer levels and globally alters the chromatin state. Mol Cell. 2010;37:457-68.

Smrt RD, Eaves-Egenes J, Barkho BZ, Santistevan NJ, Zhao C, Aimone JB, et al. Mecp2 deficiency leads to delayed maturation and altered gene expression in hippocampal neurons. Neurobiol Dis. 2007;27:77-89.

Sturm D, Witt H, Hovestadt V, Khuong-Quang DA, Jones DT, Konermann C, et al. Hotspot mutations in $\mathrm{H} 3 \mathrm{~F} 3 \mathrm{~A}$ and IDH1 define distinct epigenetic and biological subgroups of glioblastoma. Cancer Cell. 2012;22:425-37.

Sun H, Yang X, Liang L, Zhang M, Li Y, Chen J, et al. Metabolic switch and epithelial-mesenchymal transition cooperate to regulate pluripotency. EMBO J. 2020;39:e102961.

Szulwach KE, Li X, Li Y, Song CX, Wu H, Dai Q, et al. 5-hmC-mediated epigenetic dynamics during postnatal neurodevelopment and aging. Nat Neurosci. 2011;14:1607-16

Szulwach KE, Li X, Smrt RD, Li Y, Luo Y, Lin L, et al. Cross talk between microRNA and epigenetic regulation in adult neurogenesis. J Cell Biol. 2010;189:127-41.

Szwagierczak A, Bultmann S, Schmidt CS, Spada F, Leonhardt H. Sensitive enzymatic quantification of 5-hydroxymethylcytosine in genomic DNA Nucleic Acids Res. 2010;38:e181.

Tahiliani M, Koh KP, Shen Y, Pastor WA, Bandukwala H, Brudno Y, et al. Conversion of 5-methylcytosine to 5-hydroxymethylcytosine in mammalian DNA by MLL partner TET1. Science. 2009;324:930-5.

Tan HK, Wu CS, Li J, Tan ZH, Hoffman JR, Fry CJ, et al. DNMT3B shapes the mCA landscape and regulates $\mathrm{mCG}$ for promoter bivalency in human embryonic stem cells. Nucleic Acids Res. 2019;47:7460-75.

Tatton-Brown K, Seal S, Ruark E, Harmer J, Ramsay E, Del Vecchio DS, et al. Mutations in the DNA methyltransferase gene DNMT3A cause an overgrowth syndrome with intellectual disability. Nat Genet. 2014;46:385-8.

Tatton-Brown K, Zachariou A, Loveday C, Renwick A, Mahamdallie S, Aksglaede L, et al. The Tatton-Brown-Rahman syndrome: a clinical study of 55 individuals with de novo constitutive DNMT3A variants. Wellcome Open Res. 2018;3:46. 
Temple S. The development of neural stem cells. Nature. 2001;414:112-7.

Unoki M, Nishidate T, Nakamura Y. ICBP90, an E2F-1 target, recruits HDAC1 and binds to methyl-CpG through its SRA domain. Oncogene. 2004;23:7601-10.

Vitale AM, Matigian NA, Cristino AS, Nones K, Ravishankar S, Bellette B, et al. DNA methylation in schizophrenia in different patient-derived cell types. NPJ Schizophr. 2017;3:6.

Wang L, Hu M, Zuo MQ, Zhao J, Wu D, Huang L, et al. Rett syndrome-causing mutations compromise MeCP2-mediated liquid-liquid phase separation of chromatin. Cell Res. 2020b;30:393-407.

Wang Q, Yu G, Ming X, Xia W, Xu X, Zhang Y, et al. Imprecise DNMT1 activity coupled with neighbor-guided correction enables robust yet flexible epigenetic inheritance. Nat Genet. 2020a;52:828-39.

Weaving LS, Ellaway CJ, Gecz J, Christodoulou J. Rett syndrome: clinical review and genetic update. J Med Genet. 2005;42:1-7.

Weinberg DN, Papillon-Cavanagh S, Chen H, Yue Y, Chen X, Rajagopalan KN, et al. The histone mark H3K36me2 recruits DNMT3A and shapes the intergenic DNA methylation landscape. Nature. 2019;573:281-6.

Wu H, Coskun V, Tao J, Xie W, Ge W, Yoshikawa K, et al. Dnmt3a-dependent nonpromoter DNA methylation facilitates transcription of neurogenic genes. Science. 2010;329:444-8.

Wu Z, Huang K, Yu J, Le T, Namihira M, Liu Y, et al. Dnmt3a regulates both proliferation and differentiation of mouse neural stem cells. J Neurosci Res. 2012;90:1883-91.

Xu C, Zhang Y, Zheng H, Loh HH, Law PY. Morphine modulates mouse hippocampal progenitor cell lineages by up-regulating miR-181a level. Stem Cells. 2014:32:2961-72.

Xu W, Li J, Rong B, Zhao B, Wang M, Dai R, et al. DNMT3A reads and connects histone H3K36me2 to DNA methylation. Protein Cell. 2020;11:150-4.

Yan XJ, Xu J, Gu ZH, Pan CM, Lu G, Shen Y, et al. Exome sequencing identifies somatic mutations of DNA methyltransferase gene DNMT3A in acute monocytic leukemia. Nat Genet. 2011;43:309-15.

Yao B, Lin L, Street RC, Zalewski ZA, Galloway JN, Wu H, et al. Genome-wide alteration of 5-hydroxymethylcytosine in a mouse model of fragile $X$ associated tremor/ataxia syndrome. Hum Mol Genet. 2014;23:1095-107.

Yarychkivska O, Shahabuddin Z, Comfort N, Boulard M, Bestor TH. BAH domains and a histone-like motif in DNA methyltransferase 1 (DNMT1) regulate de novo and maintenance methylation in vivo. J Biol Chem. 2018;293:19466-75.

Yasui DH, Peddada S, Bieda MC, Vallero RO, Hogart A, Nagarajan RP, et al. Integrated epigenomic analyses of neuronal MeCP2 reveal a role for longrange interaction with active genes. Proc Natl Acad Sci U S A. 2007;104 19416-21.

Yin R, Mao SQ, Zhao B, Chong Z, Yang Y, Zhao C, et al. Ascorbic acid enhances Tet-mediated 5-methylcytosine oxidation and promotes DNA demethylation in mammals. J Am Chem Soc. 2013;135:10396-403.

Zhang RR, Cui QY, Murai K, Lim YC, Smith ZD, Jin S, et al. Tet1 regulates adult hippocampal neurogenesis and cognition. Cell Stem Cell. 2013;13:237-45.

Zhang Y, Xu C, Zheng H, Loh HH, Law PY. Morphine modulates adult neurogenesis and contextual memory by impeding the maturation of neural progenitors. PLoS One. 2016;11:e0153628.

Zheng H, Zhang Y, Li W, Loh HH, Law PY. NeuroD modulates opioid agonistselective regulation of adult neurogenesis and contextual memory extinction. Neuropsychopharmacology. 2013;38:770-7.

Zhu JK. Active DNA demethylation mediated by DNA glycosylases. Annu Rev Genet. 2009;43:143-66.

Zou X, Ma W, Solov'yov IA, Chipot C, Schulten K. Recognition of methylated DNA through methyl-CpG binding domain proteins. Nucleic Acids Res. 2012;40: $2747-58$

\section{Submit your manuscript to a SpringerOpen ${ }^{\circ}$ journal and benefit from:}

- Convenient online submission

- Rigorous peer review

- Open access: articles freely available online

- High visibility within the field

- Retaining the copyright to your article

Submit your next manuscript at $\boldsymbol{\nabla}$ springeropen.com 